\title{
ORÇAMENTO EM DEFESA E CAPACIDADES ESTRATÉGICAS: DISSIMILARIDADES ENTRE OS PAÍSES DA AMÉRICA DO SUL
}

\author{
Angela Nogueira Neves ${ }^{1}$ \\ Tássio Franchi ${ }^{2}$
}

\section{Introdução}

Este ar Do ponto de vista dos conflitos interestatais a América do Sul é geralmente caracterizada como uma região estável e marcada pela ausência de guerras e investimentos em defesa abaixo das médias globais (Vaz 2019), constituindo o que é comumente chamado de tradição da longa paz sul americana (Villa 2018).

No início da segunda década do século XXI, houve também a esperança de que o Conselho de Defesa e Segurança da UNASUL poderia fortalecer os laços de confiança e cooperação mútuas em defesa, o que promoveria ainda mais uma "zona permanente de paz (democrática) na América do Sul" (Villa e Souza-Pimenta 20ı6). Alguns autores questionam a tradição da "longa paz" e argumentam que existe de fato uma "paz violenta" na América do Sul. Nessa perspectiva, descartam a classificação de conflitos feita a partir de comparações extra regionais que não levam em conta tradições históricas e características dos países da região, pois não dão conta de perceber corretamente as tensões existentes entre as nações (Franchi, Migon e Jimenez 20I7). Ademais, os países sul-americanos lidam com questões de ameaças intra-estatais, como a produção e tráfico de drogas, violência urbana, tráfico ilegal de armas e ameaças ambientais para os quais, via de regra, as Forças Armadas são desdobradas (CEPAL 20I4; Costa Vaz 20I5; Andrade et al. 20I9; Oliveira 20I7).

Para pensar como os países se organizam em busca de promover sua

I Mestranda na Escola Superior de Guerra (ESG). Professora Associada na Escola de Educação Física do Exército (EsEFEx), Brasil.

2 Doutor em Desenvolvimento Sustentável pela Universidade de Brasília (UnB). Professor Adjunto da Escola de Comando e Estado Maior do Exército (ECEME), Brasil. 
Orçamento em Defesa e Capacidades Estratégicas: Dissimilaridades entre os Países da América do Sul

segurança e defesa, Barry Buzan ao propôs a teoria dos complexos regionais de segurança. Nela, ao observar a América do Sul dividiu a região em dois complexos: (i)países do cone-sul, mais pacíficos e voltado a construção de uma comunidade de segurança; e os (ii)países do arco andino, que enfrentavam mais instabilidades internas e problemas fronteiriços (Buzan et al 2003).

Mas, a concepção de Buzan sofreu críticas por não dar conta da complexidade das realidades políticas regionais (Fuccille e Rezende 20I3), e mesmo por não conseguir perceber que o orçamento de defesa e os gastos com a modernização militar não respeitam os complexos de segurança propostos.

Na verdade compras de armamentos transformam a região num único complexo regional de segurança posto que aquele não é operado unicamente nem no sistema andino nem no Cone Sul, porém por países de ambas subregiões" (Villa 20I8,I39).

Outra forma de pensar é a partir de uma visão da economia de defesa, uma vez que a mesma reflete os eventos ocorridos no país: o quanto um país separa de sua riqueza para manutenção da sua soberania e segurança, reflete o quanto o mesmo é instável e ameaçado (Hartley 20I3).

O fato é que houve no início do século XX um incremento de investimento em defesa, com aumentos dos gastos nominais e da porcentagem relativa ao PIB, refletindo em maior aquisição de tecnologia e quantidade de equipamentos pelos países da América do Sul, mais notadamente no Brasil, Chile e Venezuela. Esse comportamento fez com que, no período de 20032007 a América do Sul fosse responsável por 5\% do volume de importações de armas internacionais, sendo o montante desse período $47 \%$ superior ao período de análise anterior, I998 - 2002 (Pagliari e Sources 2010). O segundo fato que se destaca é que os investimento e orçamentos de defesa decaíram na última década, em consequência direta da crise econômica dos países sul -americanos. Não que tenha havido uma grande mudança no percentual do PIB destinado à Defesa, mas como houve queda do PIB das nações, o volume de recursos destinados ao orçamento de Defesa caiu - como aumento de gastos de pessoal e queda dos investimentos (Costa Vaz 20I9). A economia de defesa é o ramo da ciência econômica que se dedica a estas análises.

A economia de defesa trata da aplicação da teoria econômica a questões relacionadas à defesa, sendo "o raciocínio e aplicação de métodos econômicos para estudar a defesa e os aspectos econômicos relacionados a essa área” (Leske 20I8, 784). Tem foco ampliado nos estudos de paz e de guerra, abrangendo os gastos com defesa e suas consequências, o desarmamento e a paz. São de seu interesse e escopo os determinantes dos gastos com defesa - investimento e 
pessoal, incluindo orçamentos, corridas armamentistas e alianças militares (Hartley 2013).

Economia da defesa é o estudo da alocação de recursos, distribuição de renda, crescimento econômico e estabilização aplicado a tópicos relacionados à defesa. Como tal, a economia da defesa envolve uma investigação do impacto dos gastos com defesa, tanto doméstica quanto internacionalmente, sobre variáveis macroeconômicas como emprego, produção e crescimento. Também possui uma dimensão microeconômica envolvendo a análise da base industrial de defesa, programas colaborativos, compensações, a precificação e lucratividade de contratos militares e a regulamentação de empreiteiros (Hartley 2013, 6)

O desenvolvimento histórico do conceito de economia de defesa mostra a preocupação com base no conceito de "interesse nacional entendido como a integração dos interesses políticos e econômicos de uma unidade geográfica em uma nação de forma integral, fazendo-se predominar diante das idéias, políticas e ações externas" (Castro-Gómez et al. 2013, 44).

A defesa nacional, como bem público, requer políticas que permitam atender às necessidades sociais em matéria de segurança e defesa, nas quais a economia desse setor deve estar direcionada para prover as capacidades estratégicas necessárias (Jimenez 20I6). Historicamente, os países da América do Sul tem orçamentos de defesa módicos (World Bank 2020). E talvez, pela experiência de governos militares recentes, pelos poucos conflitos interestatais na região e pela comunicação precária entre o Ministério da Defesa e as Forças Armadas com a população civil, o tema Defesa e seu orçamento é pouco discutido entre esta, sendo para ela obscura a necessidade de um orçamento e defesa robusto, em detrimento de outras necessidades sociais, como educação e saúde (Almeida 20I0). Apesar dessa experiência política e cultural semelhante e dos orçamentos limitados, os países podem ser comportar de forma distinta no investimento de seu recurso econômico - dados os desafios distintos que encontram em seus territórios e em suas fronteiras - criando sua identidade de defesa, afastando-se ou aproximando-se de outros países (Fonfría 20I2).

Se as interpretações de complexos de segurança, ou tradições de longa paz ou paz violenta não dão conta de explicar totalmente como estão organizados os países Sul-americanos com relação a Defesa, podemos partir desse ponto de vista mais pragmático, os orçamentos de defesa e as capacidades materiais de defesa para compreender as dissimilaridades e aproximações entre os países da América do Sul. Isso por que as necessidades 
Orçamento em Defesa e Capacidades Estratégicas: Dissimilaridades entre os Países da América do Sul

de segurança e defesa de um país são refletidas em sua economia de defesa:

A partir da definição da missão das Forças Armadas e do planejamento estratégico, são estruturados um plano e um orçamento, com horizonte plurianual, a partir do qual é feita uma estimativa dos recursos necessários ao cumprimento dos objetivos propostos. Esses recursos são humanos, instalações físicas, equipamentos, suprimentos, tecnologia e orçamento operacional.

A economia de defesa está relacionada a duas importantes áreas de convivência nacional: econômica e defesa. Nesse sentido, busca a melhor forma de alocar recursos para dar proteção à nação, não só em períodos de conflito, mas também em tempos de paz, considerando que a escassez de recursos é uma situação permanente (Equador 20I8).

Se as interpretações de complexos de segurança, ou tradições de longa paz ou paz violenta não dão conta de explicar totalmente como estão organizados os países Sul-americanos com relação à Defesa, voltamos à pergunta desta pesquisa, como se organizam os países da América do Sul, considerando dados macroeconômicos de defesa e suas capacidades estratégicas atuais? Responder essa questão permitirá compreender reflete os eventos atuais e os cenários de ameaças considerados pelos Estados, uma vez que estes são refletidos pela economia de defesa (Hartley 2013).

A informação de proximidades entre os países, a partir da análise de dados macroeconômicos e de recursos estratégicos de defesa em conjunto, pode ser útil para que se possa planejar tratados de cooperação, investimentos em equipamentos e mesmo na base industrial de defesa em ações bi, tri ou multinacionais.

O presente estudo, a partir dos dados do Stockholm International Peace Research Institute (SIPRI) e Military Balance, analisa um conjunto de dados macro econômicos recentes, busca identificar como se organizam os países da América do Sul, determinando aqueles que são mais parecidos entre si (que formariam complexos) e como se diferem dos demais (dissimilaridades), apenas com relação às variáveis como: \% PIB para orçamento de defesa; investimento em defesa per capta; gastos em defesa; aquisições de equipamentos de defesa.

\section{Aspectos da Economia de Defesa nos Países da América do Sul}

Nessa seção, apresentaremos algumas informações acerca dos

178 Austral: Revista Brasileira de Estratégia e Relações Internacionais v.10, n.20, Jul./Dez. 2021 
indicadores macroeconômicos e investimento em defesa dos países da América do Sul. Como já afirmamos são países que historicamente pouco investem em Defesa (Tabelar).

Tabela 1 - Percentual do PIB Destinado ao Orçamento de Defesa

\begin{tabular}{|c|c|c|c|c|c|}
\hline País & 2014 & 2015 & 2016 & 2017 & 2018 \\
\hline Argentina & 0,88 & 0,85 & $0,8 \mathrm{I}$ & 0,86 & 0,85 \\
\hline Bolívia & 1,9 & $\mathrm{I}, 74$ & 1,63 & $\mathrm{I}, 54$ & $\mathrm{I}, 5$ \\
\hline Brasil & $\mathrm{I}, 33$ & $\mathrm{I}, 37$ & $\mathrm{I}, 35$ & $\mathrm{I}, 42$ & $\mathrm{I}, 47$ \\
\hline Chile & 1,96 & 1,9 & 1,92 & $\mathrm{I}, 94$ & 1,89 \\
\hline Colômbia & $3, \mathrm{I} 3$ & $3, \mathrm{I} 3$ & 3,08 & 3,19 & $3, \mathrm{I} 7$ \\
\hline Equador & 2,74 & 2,62 & $2,5 \mathrm{I}$ & 2,36 & 2,38 \\
\hline Guiana & $\mathrm{I}, 28$ & $I, 46$ & $\mathrm{I}, 5 \mathrm{I}$ & I, 68 & 1,69 \\
\hline Paraguai & 0,99 & $\mathrm{I}, 07$ & 0,95 & 0,89 & 0,93 \\
\hline Peru & $\mathrm{I}, 58$ & $\mathrm{I}, 72$ & $\mathrm{I}, 3$ & $\mathrm{I}, 24$ & I,I9 \\
\hline Uruguai & $\mathrm{I}, 8 \mathrm{I}$ & $\mathrm{I}, 82$ & $\mathrm{I}, 88$ & $I, 98$ & $\mathrm{I}, 95$ \\
\hline Venezuela & $\mathrm{I}, \mathrm{I} 6$ & 0,94 & 0,45 & 0,49 & --- \\
\hline $\begin{array}{l}\text { América Latina e } \\
\text { Caribe }\end{array}$ & 1,29 & I, 28 & $\mathrm{I}, 24$ & 1,26 & $I, 26$ \\
\hline
\end{tabular}

\section{Fonte: World Bank ${ }^{3}$ and Macro Data (especificamente para Guiana) ${ }^{4}$}

Todavia, não se pode tentar ser entender estes países como uma entidade única - América do Sul - e homogênea. Cada país tem suas particularidades. Por exemplo, a Colômbia, dedica de forma consistente um percentual mais de $3 \%$ do seu PIB acima dos $2 \%$ recomendado pela ONU (Lee 20I5). Em 20I9, Brasil (51\% do total da região; I,5\% de seu PIB), Colômbia (19\% de total da região, 3,2\% de seu PIB) e Chile (5,2\% do total de região e I, $8 \%$ de seu PIB) foram os três países com maiores orçamento de defesa na América Latina (SIPRI 20I9).

Todavia, o percentual do PIB dedicado ao orçamento de defesa não representa exatamente o montante de recursos investidos. Por exemplo,

3 Disponível em: https://databank.worldbank.org/reports.aspx?source=2\&series=MS.MIL. XPND.GD.ZS\&country=

4 Disponível em: https://datosmacro.expansion.com/estado/gasto/defensa/guyana 
Orçamento em Defesa e Capacidades Estratégicas: Dissimilaridades entre os Países da América do Sul

tomemos o Equador: O percentual do PIB é relativamente estável, mas o montante de recursos vem diminuindo ano após ano, especialmente a partir de 2014 (Figura I).

\section{Figura 1 - Gastos em Defesa (U\$ mil) nos Países da América do Sul - 2008-2019}

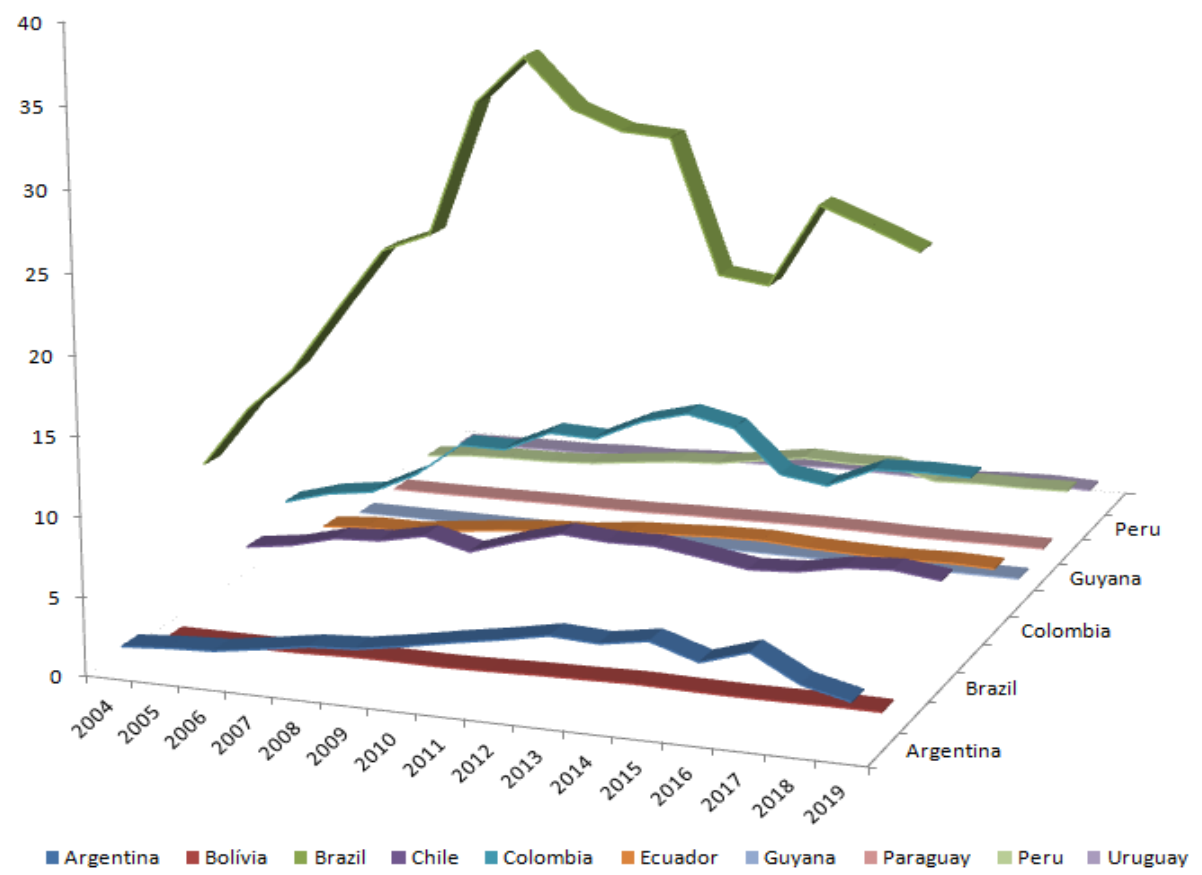

Fonte: World Bank (2020) ${ }^{5}$

No caso do Chile, apesar do montante de recursos vir paulatinamente aumentando, é estável o percentual do PIB dedicado ao orçamento de defesa.

O Chile não aumentou seus gastos com defesa como porcentagem do PIB. O indicador oscilou entre I, $7 \%$ em 200 I e $0,93 \%$ em 2016 . Adicionalmente, em relação ao comportamento de ambas as curvas ("despesa total" e "Lei Orçamentária") no mesmo período, pode Observa-se um gasto proporcionalmente homogêneo, apesar de, desde 20II, se evidenciar um estágio de estagnação ou equilíbrio dos gastos orçamentários (Chile 20I7).

5 Disponível em: https://www.macrotrends.net/countries/USA/united-states/militaryspending-defense-budget.

180 Austral: Revista Brasileira de Estratégia e Relações Internacionais v.10, n.20, Jul./Dez. 2021 
Aproximadamente na última década, especialmente Brasil, Chile, e Venezuela e em menor escala o Peru aumentaram seus gastos com aquisições e investimentos em defesa, de forma a realizar uma atualização tecnológica e suprir a insuficiência e obsolescências dos equipamentos (Costa Vaz 20I7). Especificamente o Chile ambicionava se transformar em uma potencia regional militar, atingindo o status militar OTAN (Gonzales 2005), o que ainda não veio a se concretizar. À época do início desse movimento, especulou-se que estava havendo uma "corrida armamentista na América do Sul", enquanto na verdade, era também reflexo dos períodos de crescimento econômico que estes países tiveram nesse período (Villa 20I8). As figuras 2 e 3, respectivamente sumarizam as transações de exportação e importação de armas, pelos países da América do Sul no período de 2000-20i9. O que se observa é um aumento chileno de exportação de armas em 2008, seguido por uma resposta brasileira em 20ıo. Do mais, o Brasil é o país que mais exporta armas, seguido apenas de longe pela Colômbia nos últimos 3 anos. 
Orçamento em Defesa e Capacidades Estratégicas: Dissimilaridades entre os Países da América do Sul

Figura 2 - Exportações de armas por países da América do Sul

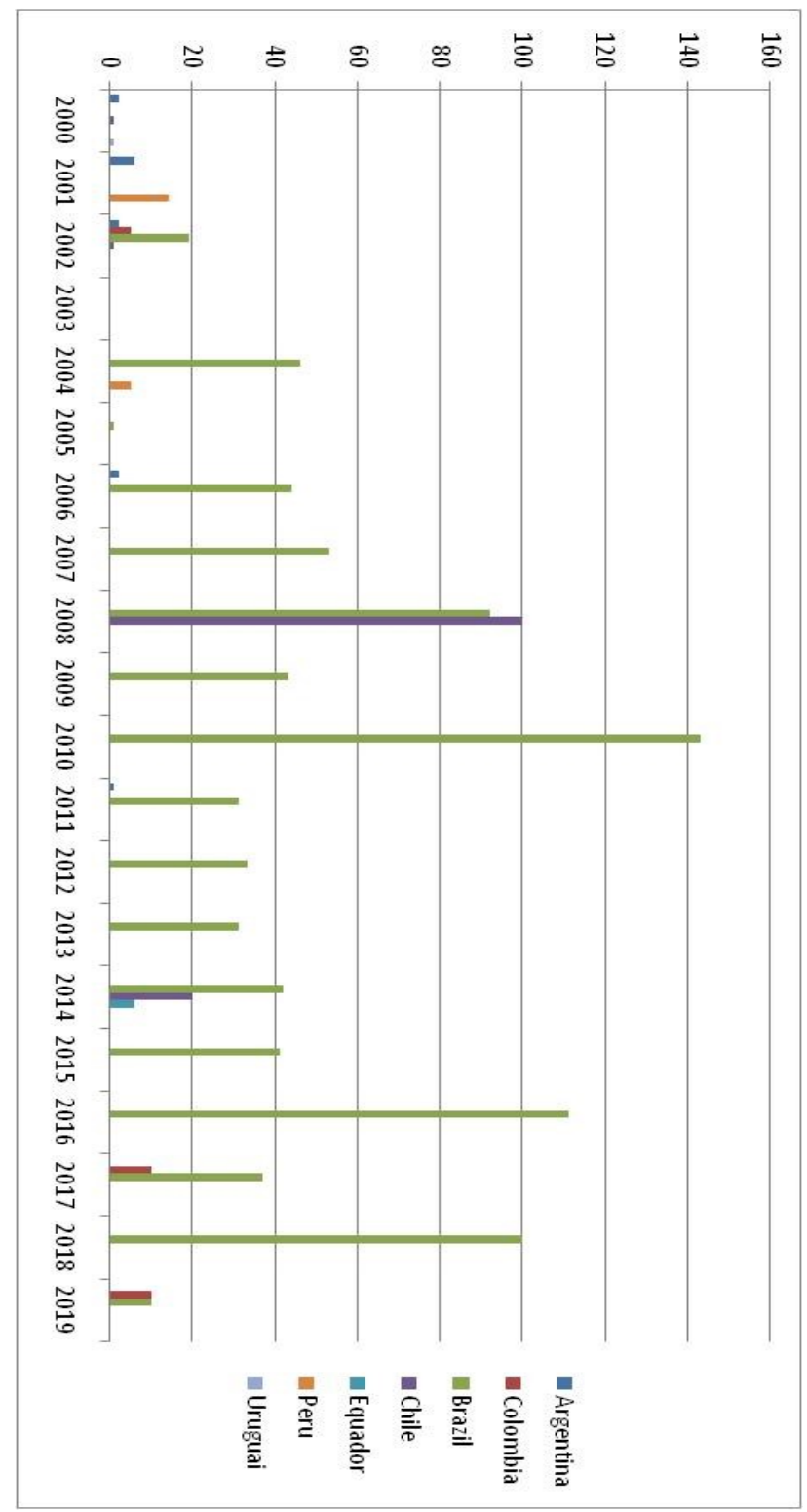

Fonte: SIPRI $2020^{6}$

6 Disponível em: http://armstrade.sipri.org/armstrade/page/toplist.php.

182 Austral: Revista Brasileira de Estratégia e Relações Internacionais v.10, n.20, Jul./Dez. 2021 
Figura 3 - Importações de armas por países da América do Sul

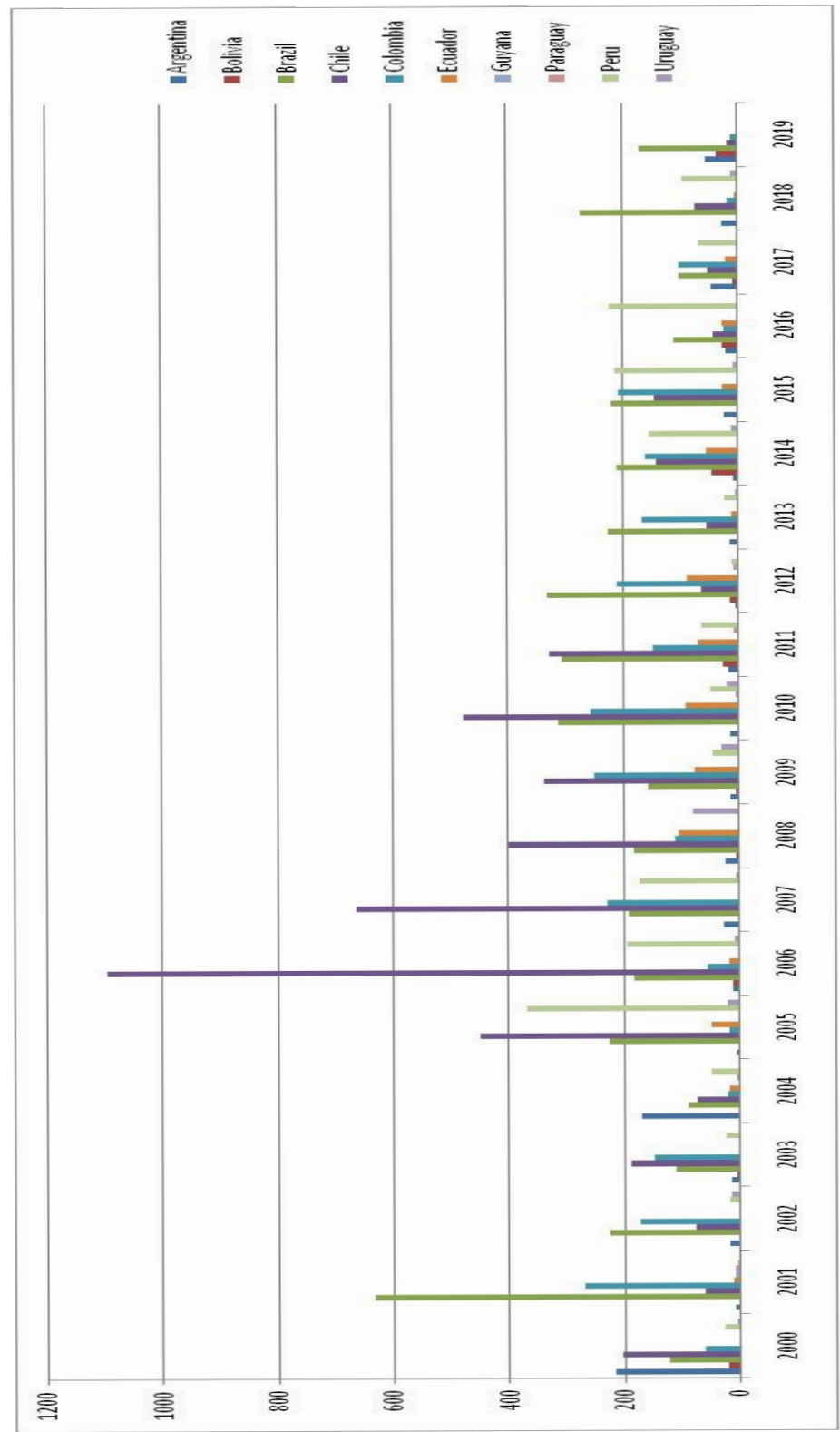

Fonte: SIPRI $2020^{7}$

7 Disponível em: http://armstrade.sipri.org/armstrade/page/toplist.php. 
Orçamento em Defesa e Capacidades Estratégicas: Dissimilaridades entre os Países da América do Sul

O movimento chileno de maior armamento a partir de 2005 provocou uma resposta dos governos peruano e argentino, países com os quais o Chile ainda tem litígios territoriais, desencadeando um aumento de investimento em defesa nesses países (Gutierrez 2007). A análise da figura 3 ainda permite inferir uma resposta do Equador, que por sua vez, tem histórico de conflitos com o Peru e Colômbia. Houve arrefecimento em todo esse movimento em 20I4-20I5 se comparado aos anos anteriores (com cortes variando entre $56,5 \%$ a $7,2 \%)$, quando os desempenhos das economias desses países declinaram, mas com retomada posterior (Costa Vaz 20I7).

Mesmo não tendo essa configuração de uma "corrida", Chile, Peru, Colômbia, Venezuela e Brasil seguem investindo na melhora de suas capacidades militares, com um orçamento de defesa estável ou levemente mais alto a cada ano (IISS 20I7). O que é interessante de observar é que nesse período de 20I4-20I5, Argentina, Colômbia, Guiana e Uruguai e Paraguai aumentaram suas despesas com defesa. Quando se analisa a questão específica do investimento na modernização militar - com aquisição e melhora dos recursos de defesa - a Argentina tem ritmo menos acentuado que o Brasil, Chile e Venezuela (Moraes 20II).

O orçamento de defesa não é completamente dedicado ao investimento em equipamentos, adestramento e financiamento de operações. Parte também é comprometida com a folha de pagamento de pessoal. A proporção média dos investimentos cai quando o orçamento total diminui - isso porque a despesa de pessoal passa a requer maior porção do orçamento, já que o número do efetivo - salvo ação direta do governo - não diminui. A esse quadro, se soma uma gestão deficitária dos recursos para limitar os investimentos em defesa.

Em um cenário severamente restrito em que os "custos fixos" em termos de pessoal representavam a maior parte do orçamento, uma administração subótima dos recursos disponíveis para custos variáveis era inaceitável. Essa realidade tornou-se uma constante em que os gastos eram aplicados de forma desnecessária e redundante em decorrência da falta de integração entre as Forças Armadas (Argentina 2010, I93).

Recentemente, entre 20I2 a 20I6, Brasil, Venezuela, Colômbia, Peru, Bolívia e Chile viram a proporção com gastos com pessoal aumentar em seus orçamentos de defesa (Brasil 2020; Costa Vaz 20I7; Chile 20I7; Peru 2005). O Equador, por sua vez, teve leve diminuição a partir de 20I4, com forte ação do governo para "aumentar a contribuição do investimento em defesa, de forma a conseguir uma instituição mais eficiente, baseada na tecnologia" (Equador 2018, I23) 
Peru e Venezuela tem um mecanismo extraorçamentário, o qual destina $20 \%$ da receita de gás do campo de Camisea para o orçamento de defesa, o que minimiza em parte o impacto das oscilações do desempenho econômicos desses países (Costa Vaz 20I7). O Chile, por sua vez, conta com a Ley Reservada del Cobre, desde I958, que realoca ı०\% dos valores obtidos com a exportação de empresas estatais de cobre para a aquisição de compra de recursos estratégicos de defesa (Silva Filho e Moraes 20I2)

O impacto na proporção do investimento pode também ser minimizado, a longo prazo, pelo desenvolvimento de uma sustentável base industrial de defesa, quer versa sobre o conjunto de empresas estatais e privadas que se dedicam à pesquisa, desenvolvimento, produção, distribuição e manutenção dos produtos estratégicos de defesa (Ferreira e Sarti 20II). Na América do Sul, o desenvolvimento dessa indústria não tem sido historicamente homogêneo, há países com uma prática mais relevante que os demais, como Brasil, Chile, Argentina e Colômbia (Parra, Játiva e Vásquez 20I9).

O desenvolvimento da indústria de defesa nos diferentes países da América do Sul depende de políticas públicas e estratégias específicas, levando em consideração que há muitas outras demandas, que não as questões de defesa ainda a se revolver, como os componentes sociais de saúde e educação. Essa realidade é generalizável para quase todas as esferas de gastos públicos, marcadas por um limitado potencial expansionista de investimento na indústria de defesa na região (Esquivel e Loaiza 20ı8).

\section{Métodos}

Esta pesquisa tem delineamento de pesquisa transversal, sendo de cunho exploratório, utilizando-se de dados discretos e contínuos (Gil 20I7).

\section{Dados e Fonte de Dados}

Duas fontes de dados foram consultadas para esta pesquisa. As informações acerca dos indicadores macroeconômicos analisados (orçamento de defesa; \% do PIB para o orçamento de defesa; orçamento de defesa per capta; \% do orçamento de defesa na despesa do governo), do pessoal da ativa e dos dados relativos à importação eexportação de armas foram coletados no Stockholm International Peace Research Institute (SIPRI), considerandose o ano base de 20I9. Dos onze países e um território ultramarino francês que compõem a América do Sul, havia dados sobre Argentina, Bolívia, Brasil, Chile, Colômbia, Equador, Guiana, Paraguai, Peru e Uruguai. Foram 
Orçamento em Defesa e Capacidades Estratégicas: Dissimilaridades entre os Países da América do Sul

especificamente consultados as bases de dados Data for all countries from 1988-2019 in constant (2018) USD e Data for all countries from 1988-2019 as a shareof GDP

O oitavo capítulo do relatório 2020 do Military Balance (base de dados de 2019), intitulado America Latina and Caribean, foi consultado para o recolhimento dos dados acerca dos equipamentos e pessoal ativo. Dados de todos os países da América do Sul foram ali encontrados.

\section{Procedimentos}

Na plataforma do SIPRI os dados foram consultados para os países disponíveis e transcritos em planilha excel, mantendo a moeda de referência (dólar americano).

No Military Balance os dados foram consultados e transcritos apenas para aqueles países que também estavam presentes no SIPRI. Foram registradas a quantidade de capacidades - como por exemplo: armas, helicópteros, naves de transporte e combate, mísseis - por tipo de Força (Exército, Marinha - incluindo aviação naval e mariners - e Aeronáutica) presente no documento para cada país. Foi registrado o número total de capacidades para cada categoria, mas sem especificar a quantidade por tipo de equipamento (Ex.: consta na força aérea Brasileira cinco helicópteros de transporte de três diferentes modelos. É o número total que foi registrado, e não o por modelo de equipamento).

Os autores confeccionam a planilha de forma independente. As polanilhas foram conferidas de forma cruzada pelos pesquisadores, de forma a identificar erros de registo e mesmo interpretação dos dados. Esse procedimento foi tomado para garantir a confiabilidade das informações analisadas. Apenas 4 ocorrências em um total de 83 variáveis foram identificadas, tendo sido as mesmas conferidas e corrigidas. Após esse processo, os dados foram transferidos para a planilha de análise do software SPSS 22 para análise estatística.

\section{Análise Estatística}

Para alcançar o objetivo desta pesquisa, optou-se por uma abordagem multivariada descritiva e não inferencial, exploratória em essência, a análise de cluster. A análise de cluster por conglomerados é uma técnica estatística multivariada de interdependência utilizada para combinar observações 
em agrupamentos ou clusters. Em outras palavras, ela classifica objetos (respondentes, variáveis), separando grupos com homogeneidade interna e, ao mesmo tempo, dessemelhantes entre si (Hair et al 2009).

Com a análise hierárquica de clusters busca-se que :i) cada grupo ou cluster seja homogêneo em certas características. Ou seja, as observações de um grupo são similares às do outro; ii) cada grupo deva ser diferente dos demais grupos em relação às mesmas características, isto é, as observações de um grupo devem ser diferentes das observações dos outros grupos (Sharma I996).

A identificação dos clusters se baseia no incremento das distancias entre cada estágio de aglomeração. Quando os incrementos aumentam substancialmente, indica que está se aglomerando países pouco homogêneos, sendo indicativo de o cluster deve ser formado pelas variáveis ou casos pertencentes ao estágio anterior (HAIR et al. 2009).

Por causa do caráter exploratório deste estudo e por não haver, a priori, o estabelecimento de relações causais em potencial e, por conseguinte, do número de clusters, os sete métodos de aglomeração hierárquicos, com e sem normalização pelo escore Z, foram testados para verificar qual separaria melhor os países analisados. Determinou-se que a medida de distância euclidiana seria usada para inferir as (des)semelhanças entre as variáveis, por ser uma das mais usadas na análise de cluster (Malhotra, I999). Adotou-se a seleção listwise, para evitar viéses nos resultados. O software SPSS, versão 22 , foi usado nas análises.

\section{Resultados}

O método hierárquico de Ward com o intervalo determinado a partir da distância euclidiana ao quadrado, e variáveis normalizadas pelo escore Z por caso, foi o que mostrou melhor separação das variáveis e os resultados aqui apresentados dizem respeito àqueles gerados pela análise com este método hierárquico de aglomeração. O dendograma da solução da análise do cluster indica a existência de quatro clusters distintos (Figura 4; Tabela 2). 
Orçamento em Defesa e Capacidades Estratégicas: Dissimilaridades entre os Países da América do Sul

Tabela 2 - Padrões de Aglomeração

\begin{tabular}{|c|c|c|c|c|}
\hline \multirow[t]{2}{*}{ Estágio } & \multicolumn{2}{|c|}{ Combinação } & \multirow{2}{*}{$\begin{array}{l}\text { Coeficiente de } \\
\text { aglomeração }\end{array}$} & \multirow{2}{*}{$\begin{array}{l}\text { Próximo } \\
\text { Estágio }\end{array}$} \\
\hline & Variável & Variável & & \\
\hline 1 & 4 & 9 & 0,57 & 3 \\
\hline 2 & 3 & 5 & 1,41 & 6 \\
\hline 3 & 1 & 4 & 2,81 & 5 \\
\hline 4 & 6 & 8 & 4,69 & 6 \\
\hline 5 & 1 & 2 & 7,55 & 7 \\
\hline 6 & 3 & 6 & 10,60 & 8 \\
\hline 7 & 1 & 10 & 17,37 & 8 \\
\hline 8 & 1 & 3 & 28,65 & 9 \\
\hline 9 & 1 & 7 & 75,09 & 0 \\
\hline
\end{tabular}

Figura 4 - Clusters dos Países da América do Sul

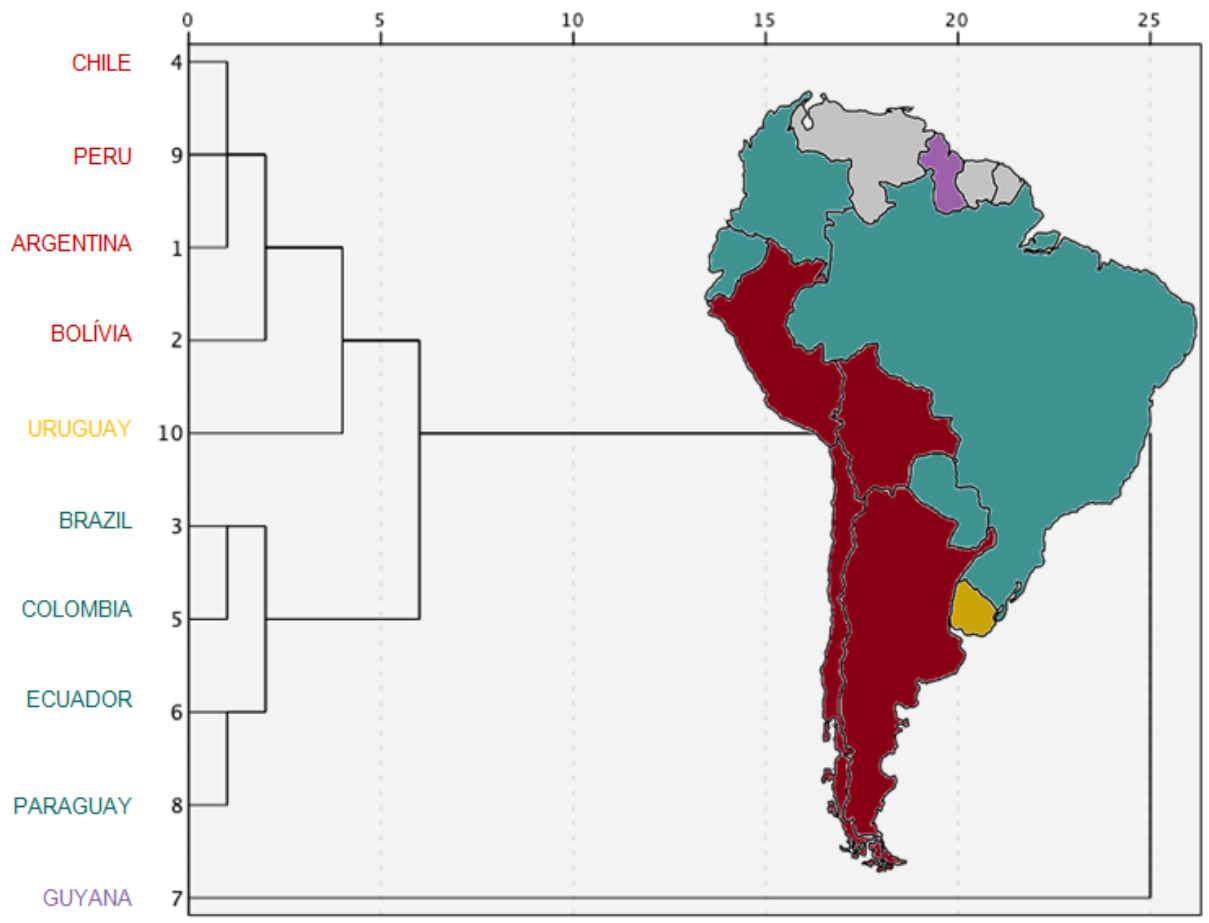

188 Austral: Revista Brasileira de Estratégia e Relações Internacionais v.10, n.20, Jul./Dez. 2021 
O primeiro cluster é formado por Chile, Peru, Argentina e Bolívia. Considerando o conjunto de variáveis analisadas, estes países são os mais similares, mas não de forma homogênea. Nesse cluster, Chile, Peru e Argentina são os países mais próximos, havendo uma proximidade no segundo estágio entre Bolívia especificamente com a Argentina.

No segundo cluster, encontramos dois pares de países mais próximos: Brasil e Colômbia; e Equador e Paraguai. No segundo estágio desse cluster, Brasil e Equador são os países mais próximos. Nesses grupos, a proximidade dos países é ainda maior que no primeiro cluster.

Por fim, o terceiro e quarto cluster são formados por dois países isolados: a Guiana e o Uruguai.

\section{Discussão}

A presente pesquisa objetivou identificar aqueles países da América do Sul que são mais parecidos entre si (que formariam clusters) e como se diferem dos demais (dissimilaridades), considerando dados macroeconômicos de defesa e dados de recursos estratégicos de defesa disponíveis no Stockholm International Peace Research Institute (SIPRI) e Military Balance, através de uma análise multifatorial, exploratória em sua essência.

Este trabalho é uma provocação evidenciada para repensarmos como os países da América do sul podem se organizar, em uma tentativa de superar as propostas de seu entendimento trazidas pelos complexos de segurança, pela tradições de paz longa e da paz violenta, que tem suas limitações. As evidencias aqui geradas podem fomentar uma nova perspectiva e justamente, gerar subsídios para essa nova visão era nossa proposta principal.

Quanto aos que foi aqui identificado, os dados apontam que a Guiana seria um país isolado dos demais. Apesar de dividir tensões territoriais com a Colômbia em relação à migração Venezuelana e de compartilhar dos problemas de ilícitos transnacionais na região amazônica com os países da Pan-Amazônia (Costa Vaz 20I7), este é um país novo, independente apenas em Ig66 do Reino Unido, com colonização originalmente holandesa. Além dessa diferença cultural, diferente dos outros países da região experimenta um "boom "econômico, com a descoberta recente de jazidas de petróleo em sua costa, com crescimento estimado em $85 \%$ pelo FMI para esse ano de 2020 (Guiana 2020), o que poderá permitir deixar de ser o segundo país mais pobre da América do Sul. Sua estruturação recente como país independe, sua situação econômica peculiar permite compreender a posição única da Guiana no continente evidenciada nos resultados. 
Orçamento em Defesa e Capacidades Estratégicas: Dissimilaridades entre os Países da América do Sul

O cluster formado por Brasil, Colômbia, Equador e Paraguai é o que estabeleceu maior es relações de proximidade, com dois pares de países muito próximos - Brasil e Colômbia; Equador e Paraguai. Apesar de serem países de "blocos geográficos" distintos, o Equador um país andino e o Paraguai um país do cone sul, Equador e Paraguai tem semelhanças em relação à sua baixa dimensão territorial - que poderia levar a uma interpretação errônea de que por isso teriam uma demanda menor de investimento em recursos de defesa para resguardar sua segurança e soberania. Mas, o Equador tem um passado de conflitos interestatais com algumas pendencias ainda existentes - o que por sua vez, exigem um permanente investimento em quantidade e qualidade dos recursos estratégicos de defesa (Villa 20I8). E o Paraguai por sua vez utiliza suas Forças Armadas também em ações de segurança pública, especialmente no combate grupos e facções criminosas ligados a ilícitos, quando ao combate ao Exército do Povo Paraguaio (EPP) .

Brasil e Colômbia por sua vez, são as duas grandes potências da região, ambos países Pan-Amazônicos. São os dois responsáveis pela maior parcela orçamentária de defesa da região, com maior quantidade de recursos estratégicos de defesa. Os dois países vêm atuando conjuntamente na fiscalização das fronteiras amazônicas e dividem questões muito semelhantes de segurança pública, com ameaça da autoridade do Estado frente à ação do narcotráfico. Em 20I9, o Brasil teve um aumento de 450 milhões de dólares em seu orçamento de defesa, seguido pela Colômbia com um aumento próximo de 300 milhões de dólares. Os Brasil é um dos países mais capacitados de região, mas a Colômbia teve uma melhor importante em seus recursos estratégicos de defesa, mantendo seu orçamento estável com tendência à alta (IISS 2020). Mesmo tendo uma boa parcela dos recursos de defesa comprometidos com pagamento de pessoal, como estes países historicamente tem orçamentos mais altos na região para defesa, eles se aproximam de forma mais significante entre si em relação aos demais.

Ainda nesse cluster, o Equador é também próximo do Brasil - menos que a Colômbia, mas ainda assim de forma relevante. Os países lidam com demandas muito distintas em termos de defesa: enquanto o Equador lida com ameaças externas, o Brasil tem as questões de violência interna, com áreas onde o monopólio da violência por parte do Estado é posto em xeque, como nas comunidades do Rio de Janeiro e nas fronteiras nacionais a questão dos ilícitos. O Equador tive um incremento especial na década de I990 com a Guerra do Cenepa (I995), tendo o país recebido um orçamento de defesa consideravelmente mais alto que o atual para sua manutenção e atualização tecnológica. "Em função das mudanças na arena internacional, em um período relativamente curto de tempo, Estados modificaram rapidamente o seu

190 Austral: Revista Brasileira de Estratégia e Relações Internacionais v.10, n.20, Jul./Dez. 2021 
comportamento em relação aos seus gastos militares" (Heye 2015, I25). Tem também comportamentos diferentes em termos de investimentos: o Equador está na direção de aumentar os investimentos em defesa, cortando os gastos com pessoal e mantendo constante o percentual do PIB aplicado, apenas de haver diminuição real do montante investido. O Brasil compromete boa parte de seu orçamento de defesa com pessoal, importa e exporta armas de forma muito distinta do Equador, aumentando nos últimos anos o percentual do PIB e o montante real destinado ao orçamento de defesa. Então, como explicar as semelhanças identificadas?

Um ponto em comum, entre Paraguai, Equador, Brasil e Colômbia é o uso de suas Forças Armadas em ações de segurança pública em especial no combate à ilícitos e facções criminosas internacionais. As origens, as trajetórias históricas das origens, os ramos de atuação e as capacidades bélicas de cartéis de drogas, facções criminosas, narco-guerrilhas dentre outros atores violentos não-estatais são distintas em cada país, mas não são alvo de investigação deste texto ${ }^{8}$. Esse apontamento, não encerram a necessidades de estudos mais detalhados comparando os países dentro do cluster que o estudo identificou.

No outro cluster, Chile, Peru, Bolívia e Argentina são países muito próximos entre si. Além de serem países andinos, dividem tensões fronteiriças, o que os levam a buscar equiparar suas capacidades estratégicas de defesa (Gutierrez 2007). Desde a perda do acesso ao mar na Guerra do Pacífico, século XIX, a Bolívia tem uma demanda histórica por parte do território chileno. O aumento abrupto de $\%$ do PIB destinado à defesa, na aquisição de armas promovido pelo Chile na primeira década do século XXI pode explicar essa similaridade identificada nesses países, em uma onda de resposta ao movimento de maior armamento chileno. À medida que o Chile foi aplicando recursos na aquisição de melhores e maior quantidades de capacidades estratégicas de defesa, houve a resposta de seus vizinhos Peru e Argentina (em menor grau), países com o quais tem disputas históricas (Franchi, Migon e Jimenez 20I7), senso esse um movimento esperado na ótica da economia de defesa (Leske 20I8). Por outro lado, Chile e Argentina tem construído uma agenda de cooperação em defesa, com destaque para a criação da Força de Paz Conjunta-Combinada Cruz del Sur, que ajuda a criar uma identidade de defesa bi-nacional, exigindo recursos aplicados de ambos os países (AITA 2020). Diferente do Chile, as Forças Armadas Argentinas sofrem da deterioração paulatina desde a derrota na Guerra das Malvinas (I982), assim como a Bolívia, vem recebendo cada vez menos recursos para o setor da defesa, o que tem como consequência equipamentos e instalações

8 Para saber mais ver: Ferreira e Framento 2020; Valera 2018. 
Orçamento em Defesa e Capacidades Estratégicas: Dissimilaridades entre os Países da América do Sul

deterioradas (IISS 2020).

Com estes argumentos parciais podemos observar esse cluster tem em comum rivalidades fronteiriças adormecidas, com origens que remontam aos séculos XIX e XX, e que com exceção do Chile, os três países enfrentaram derrotas militares e perdas territoriais. Entendemos que esse cenário é o responsável por apontar a similaridade apenas entre estes três países nesse cluster. Se o orçamento de defesa e os gastos em defesa são de fato um reflexo das necessidades e estratégias de defesa de um país, esse cluster identifica bem este fato.

Por fim, o Uruguai se destaca isolado dos demais países. País de pequena dimensão, tem mantido o \% do PIB dedicado à defesa relativamente estável, mas com decréscimo contínuo do montante do orçamento de defesa desde 20I4. Esses dados o coloca próximo de vários países, mas o Uruguai parece ser realmente um caso à parte na América do Sul:

O Uruguai ... tem apenas 3,4 milhões de habitantes, mas está entre os dez maiores contribuintes de tropas para o PKO da ONU (Operações de Manutenção da Paz) e é o primeiro contribuinte per capita. Em 2002 e 2003, era o sétimo contribuinte de tropas para a ONU e, no final de 2005 , era o oitavo no ranking da ONU. O Uruguai nunca teve qualquer ameaça externa iminente à sua segurança após sua independência em I828, e não teve nenhuma ameaça interna desde o fim das ações da guerrilha urbana na década de 1970. O país não possui indústria de defesa, e sempre teve um serviço militar totalmente voluntário, que atualmente envolve quase ı\% da população total e cerca de $2 \%$ da força de trabalho [...]. Os gastos uruguaios com defesa foram influenciados principalmente por fatores internos, em sua maioria de natureza econômica (Pelaéz 2007, 28I)

Com essas características, é possível ratificar a posição distinta do Uruguai em relação ao demais países da América do Sul, em termos de recursos estratégicos de defesa, que são muito mais voltados aos problemas internos, e às ações em missões de paz, distante do continente.

\section{Considerações Finais}

A partir dos dados do Stockholm International Peace Research Institute (SIPRI) e Military Balance, analisamos um conjunto de dados macro econômicos recentes (\% PIB para orçamento de defesa; investimento em defesa per capta; gastos em defesa; capacidades) e a quantidade e tipos de gastos por Forças Armadas, identificamos que é possível, a partir dessa 
vertente compreender os países da América do Sul organizados em quatro clusters, refletindo sobre suas similaridades em termos macroeconômicos do orçamento de defesa ao longo do tempo.

Apesar de sua contribuição à compreensão das dinâmicas na América do sul a partir de uma vertente econômica, a pesquisa é limitada pela ausência dos dados de Venezuela, Suriname e da Guiana Francesa (território francês ultramarino) - o que cabe à ele no orçamento de defesa Francês. Pesquisas futuras podem usar outras bases de dados a fim de suprir essa lacuna. De igual maneira, podem explorar comparações entre os países de cada cluster de outros aspectos como o histórico de missões militares estrangeiras, evolução das doutrinas militares, noções de ameaças nos documentos de defesa nacionais de casa país; desenvolvimento da base industrial de defesa de cada país, bem como outros temas.

O valor desta pesquisa está no uso de análises estatísticas para analisar os dados macroeconômicos e determinar aproximações - clusters aparentemente não naturais, quando pensamos nos países apenas por lentes teóricas como dos complexos regionais de segurança.

\section{REFERÊNCIAS}

Aita, Edson. 2020. "A Força De Paz Conjunta-Combinada Cruz Del Sur Como Catalisadora Da Construção De Uma Identidade De Defesa Regional.”. Ph.D, Escola de Comando e Estado - Maior do Exército.

Almeida, Carlos Wellington de. 2010. "Política De Defesa No Brasil: Considerações Do Ponto De Vista Das Políticas Públicas”. Opinião Pública i6 (I): 220-250. doi:I0.1590/so104-62762010000I00009.

Andrade, Israel, Valerio Lange, Oscar Medeiros Filho, and Raphael Lima. 2019. Desafios Contemporâneos Para O Exército Brasileiro. Ist ed. Brasilia: IPEA.

Argentina. 20I0. "Libro Blanco De La Defensa". Buenos Aires: Ministério de la Defensa.

Brazil. 2020. "Livro Branco De Defesa Nacional”. Brasilia: Ministerio da Defesa.

Brazil, Agência Brasileira de Desenvolvimento Industrial, Marcos José Ferreira, and Fernando Sarti. 20II. Diagnóstico: Base Industrial De Defesa Brasileira. Ist ed. Campinas: ABDI, NEIT-IE-UNICAMP.

Buzan, Barry, and Ole Wæver. 2003. Regions And Powers: the structure of international security. Cambridge: Cambridge University Press. 
Orçamento em Defesa e Capacidades Estratégicas: Dissimilaridades entre os Países da América do Sul

Castro-Gómez, Santiago, Alberto Flores-Malagón, Guillermo Vásquez, and Carmem Benavides. 2007. Pensamiento Colombiano Del Siglo XX. Bogotá: Pontificia Universidad Javeriana.

CEPAL (Comisión Económica para América Latina y el Caribe). "UNASUR: Un Espacio De Cooperación E Integración Para El Desarrollo". 202I. Comisión Económica Para América Latina Y El Caribe. http:// ceed.unasursg.org/Espanol/ogDownloads/Biblioteca/UNASURCOOPERACION.pdf.

Chile. 2021. "Libro De La Defensa Nacional De Chile". Santiago: Ministerio de Defensa Nacional.

Costa vaz, Alcides. 202I. “Tendências E Perspectivas Sobre Gastos Militares Dos Países Amazônicos: Implicações Para Os Objetivos E Interesses De Defesa Do Brasil". In Desafios Contemporâneos Para O Exército Brasileiro, Ist ed., 37-58. Brasilia: IPEA.

Ecuador. 20I8. "Política De La Defensa Nacional Del Ecuador: "Libro Blanco". Quito: Instituto Geográfico Militar.

Esquivel Monge, Manfred, and Kerry Loaiza Marín. 20I8. "Inversión En Infraestructura Y Crecimiento Económico, Relevancia De Factores Institucionales". Economía Y Sociedad 23 (53): 40-6I. doi:Io.I5359/ eys.23-53.3.

Ferreira, M. A. S., \& Framento, R. S. 2020. Atores não-estatais violentos transnacionais na América do Sul: um exame dos casos do Primeiro Comando da Capital e da Família do Norte. Revista Brasileira de Segurança Pública, I4(I), 72-87.

Franchi, Tássio, Eduardo Xavier Ferreira Glaser Migon, and Roberto Xavier Jiménez Villarreal. 20I7. "Taxonomy Of Interstate Conflicts: Is South America A Peaceful Region?”. Brazilian Political Science Review II (2): e0008 I-23. doi:I0.I590/I98I-382I20I700020008.

Fonfria, Antonio. 20I2. "Sobre La Naturaleza Y Alcance De La Economía De La Defensa.”. Revista Del Instituto Español De Estudios Estratégicos 79: I-2I. https://dialnet.unirioja.es/servlet/articulo?codigo=7471052.

Fuccille, Alexandre, and Lucas Pereira Rezende. 2013. "Complexo Regional De Segurança Da América Do Sul: Uma Nova Perspectiva”. Contexto Internacional 35 (I): 77-I04. doi:Io.I590/so102-85292013000100003. Gil, Antonio. 20I7. Como Elaborar Projetos De Pesquisa. São Paulo: Atlas..

Gonzalez Cabera, P. 2005. "Chilean Military Plans To Be Military-Standard For NATO For 2010". El Mercurio, 2005.

Guyana. 2020. "Oficina De Información Diplomática". Exteriores.Gob.Es. 
http://www.exteriores.gob.es/Documents/FichasPais/Guyana_ FICHA\%20PAIS.pdf.

Gutiérrez, Carlos. 2007. "Chile, Perú Y Bolivia: Entre El Conflicto Y La Cooperación". In Seguridad Humana Y Nuevas Políticas De Defensa En Iberoamérica, 29I-32I. Madrid: Instituto Universitario General Gutiérrez Mellado.

Hair, Joseph F, William C Black, Barry J Babin, and Rolph E Anderson. 2009. Multivariate Data Analysis. London: Pearson..

Hartley, Keith. 2003. Handbook Of Defense Economics. Amsterdam: Elsevier.

Heye, Thomas Ferdinand. 20I5. "Democracia, Controle Civil E Gastos Militares No Pós-Guerra Fria: Uma Análise Realista”. Carta Internacional io (I): I05 - I34. doi:IO.21530/ci.vioni.20I5.206.

IISS - International Institute for Strategic Studies. 20I7. Military Balance 2017: The Annual Assessment Of Global Military Capabilities And Defence Economics. London: ISS.

IISS - International Institute for Strategic Studies. 2020. Military Balance 2020: The Annual Assessment Of Global Military Capabilities And Defence Economics. London: ISS.

Jimenez, José Lorenzo. 20I6. “Un Análisis Macroeconómico De Los Efectos De La Inversión En Defensa Nacional Sobre La Base Industrial Y Tecnológica En España.”. Ph.D, Universidad Rey Juan Carlos.

Lee, Robert Victor. 202I. "China Builds Space-Monitoring Base In The Americas". The Diplomat. https://goo.gl/6rHNYv.

Leske, Ariela. 20I8. "Economia De Defesa". In Dicionário de Segurança e Defesa, 784-8ı. São Paulo: Editora UNESP.

Malhotra, Naresh K. 20I2. Pesquisa De Marketing: uma orientação aplicada. Porto Alegre: Bookman.

Moraes, Rodrigo. 20II. "A Indústria De Defesa Na Argentina”. Boletim De Economia E Política Internacional 6: 49-6r. http://repositorio.ipea. gov.br/bitstream/II058/46I9/I/BEPI_n6_industria.pdf.

Oliveira, Marcos Guedes. 20I7. “Ameaças Regionais E Extrarregionais E As Respostas Do Brasil”. Revista Artigos Estratégicos 3 (2): I5 - 27. http:// ebrevistas.eb.mil.br/index.php/CEEExArE/article/view/I277..

Pagliari, Graciela. 20ıо. "Gastos Militares Na América Do Sul: Considerações Acerca Dos Investimentos No Período Pós-Guerra Fria”. Diálogo I6 (I): I3 - 29. doi:I0.18316/68.

Parra, Cárdenas, Salvador Játiva, and Freddy Vasquez. 20I9. "Industria De La Defensa Y Desarrollo De Capacidades Estratégicas En Ecuador”. 
Orçamento em Defesa e Capacidades Estratégicas: Dissimilaridades entre os Países da América do Sul

Revista Internacional Del Mundo Económico Y Del Derecho I7: I -I2..

Peláez, Amílcar. 2007. "Country Survey XX: Defence Spending And Peacekeeping In Uruguay”. Defence And Peace Economics I8 (3): 28I302. doi:Io.1080/10242690600924679.

Peru. 2005. “Libro Blanco De Aa Defensa Nacional.”. Lima: Ministerio de la Defensa.

Salgado, Vitória Totti. "Conflito no norte do Paraguai: entre a força-tarefa conjunta e o Exército do Povo Paraguaio". Dossiê de Conflitos Contemporâneos. Volume I, Número I: 49-54.

Sharma, Subhash. 2008. Applied Multivariate Techniques. New York, NY: Wiley \& Sons.

Silva Filho, Edison, and Rodrigo Moraes. 2013. Da Guerra Contra O Terror ^̀ Crise Econômica Internacional: Perspectivas Para A Defesa Brasileira Em Um Cenário De Transição Nos Gastos Militares Mundiais. Brasilia: IPEA.

SIPRI - Stockholm International Peace Research Institute. 2020. "4. Military Expenditure | SIPRI”. SIPRI Yearbook 2019. https://www.sipri.org/ yearbook/2019/04.

Villa, Rafael, and Marilia Carolina De Souza Pimenta. 20I7. "A Longa Paz Na América Do Sul: Questionamentos Às Teses Da Paz Negativa Na Região". Papel Político 2I (2): 435- 468. doi:Io.III44/javeriana.papozI2.lpas.

Villa, Rafael. 20I8. "Armament Modernization In South America: Empirical And Theoretical Pressures On The Dualistic Views Of Regional Security". AUSTRAL: Brazilian Journal Of Strategy a International Relations 7 (I4): I38-I63. doi:I0.22456/2238-6912.87990.

World Bank. 2020. "Gasto Militar (\% Del PIB) | Data”. Datos.Bancomundial. Org.https://datos.bancomundial.org/indicator/MS.MIL.XPND. GD.ZS?view=chart. 


\section{RESUMO}

Levamos em consideração que as interpretações dos complexos de segurança, das tradições de paz longa e da paz violenta não explicam completamente como os países sul-americanos estão organizados em relação à Defesa. Diante disso, executamos uma análise de cluster com dados Stockholm International Peace Research Institute (SIPRI) e relatório do Military Balance com despesas de defesa econômica e investimento em capacidades de países sul-americanos. Essa técnica permite identificar como os países estão organizados, determinando aqueles que são mais semelhantes entre si (que formariam complexos) e como eles diferem dos outros (dissimilaridades). Os resultados mostraram quatro clusters diferentes: o primeiro formado por Chile, Peru, Argentina e Bolívia; a segunda por Brasil, Colômbia, Equador e Paraguai; a terceira apenas pela Guiana; e a quarta, formada apenas pelo Uruguai. Interpretamos esses clusters considerando o histórico de conflitos, atualmente ameaças e tratados de países.

\section{PALAVRAS-CHAVE}

Defesa Econômica,; América do Sul; Capacidade de Defensa; Gasto em Defensa.

Recebido em 31 de agosto de 2021 Aprovado em 07 de dezembrol de 2021 